\title{
Клінічні випадки лікування кісткового ураження при раку грудної залози та передміхурової залози (радіонуклідна терапія)
}

\author{
Національний інститут раку, Київ \\ Одержано: 27.05 .2020 \\ Прийнято до друку: 03.07.2020 \\ DOI: $10.32471 /$ clinicaloncology.2663-466X.37-1.26931
}

\begin{abstract}
Мета дослідження - підвищити ефективність лікування та визначити місце радіонуклідної терапії самарієм (153 $\mathrm{Sm}$ ) оксабіфором в лікуванні метастатичного ураження кісток при злоякісних пухлинах різної локалізації. Об'єкт та методи. Результати лікування за допомогою ${ }^{153} \mathrm{Sm}$ оксабіфору. 120 хворих з первинними пухлинами передміхурової залози та грудної залози і метастатичним ураженням кісток. До групи спостереження увійшли 75 пацієнток з раком грудної залози і 45 пацієнтів з раком передміхурової залози. Результати. До призначення радіонуклідної терапії всі пацієнтки з раком грудної залози одержували хіміотерапевтичне лікування, бісфосфонати та гормони. Вираженість болю в кістках зменшувалася під впливом протипухлинних препаратів, однак ступінь зменшення больового синдрому з часом знижувався. У всіх хворих на рак передміхурової залози спостерігався больовий синдром, який потребував збільшення кількості знеболювальних препаратів. Причиною призначення радіонуклідної терапії стало збільшення вираженості больового синдрому та кількості прийомів знеболювальних препаратів. 3 метою знеболення та профілактики переломів і подальшого метастатичного прогресування в кістках хворим за показаннями призначалася терапія ${ }^{153} \mathrm{Sm}$. Діагностичне сканування проводили через 3-4 міс після лікування ${ }^{153} \mathrm{Sm}$. У 75\% відмічено зменшення больового синдрому, зниження функціональної активності метастатичних вогнищ (нижчий відсоток накопичення радіоактивного фармацевтичного препарату та у $48 \%$ пацієнтів зменшувалася кількість вогнищ ураження в кістках. Висновки. Доведено, що радіонуклідна терапія $3{ }^{153} \mathrm{Sm}$ оксабіфором може бути застосована в комплексному лікуванні метастатичного ураження кісткової системи при злоякісних пухлинах різної локалізації. ${ }^{153} \mathrm{Sm}$ оксабіфор характеризується високим рівнем накопичення радіоактивного фармацевтичного препарату у метастатичному вогнищі при мінімальних побічних ефектах.
\end{abstract}

Ключові слова: рак грудної залози, рак передміхурової залози, самарій оксабіфор $\left({ }^{153} \mathrm{Sm}\right)$, метастатичне ураження кісток.

\section{вступ}

Сучасні методи лікування кісткових метастазів включають радіочастотну абляцію, променеву терапію, хірургію, за наявності одиничних вогнищ метастазування, хіміо-, гормоно-, радіонуклідну терапію, введення бісфосфонатів при дифузному множинному ураженні скелета. Однак навіть на тлі комплексного застосування доступних терапевтичних модальностей нерідко спостерігається прогресування метастатичного процесу і посилення больового синдрому. У зв'язку із цим проблема пошуку нових методів лікування такої категорії пацієнтів залишається актуальною.

Найбільший досвід успішного застосування радіонуклідів у паліативній терапії накопичений при раку передміхурової залози і раку грудної залози, що пояснюється характером ураження кісткової системи (наявність вираженого бластного компоненту) [1, 2, 3].

Упродовж останніх 10 років в Україні в ядерній медицині широко застосовується препарат третьої генерації - самарій $\left({ }^{153} \mathrm{Sm}\right)$ оксабіфор. Поєднання $\beta$ - і $\gamma$-випромінювання в спектрі препарату, відносно короткий період напіврозпаду, що становить 46,3 год, а також невисока енергія випромінювання $(0,81 \mathrm{MeB})$ обумовили його широке використання для паліативного лікування множинного метастатичного ураження скелета. Терапевтична дія ${ }^{153} \mathrm{Sm}$ оксабіфору визначається його $\beta$-випромінюванням, а наявність у його спектрі $\gamma$-складової дозволяє реєструвати накопичення і розподіл препарату в патологічних осередках за допомогою $\gamma$-камери, i, таким чином, здійснювати моніторинг проведеної терапії $[4,5,6]$.

\section{МЕТА ДОСЛІДЖЕННЯ}

Метою дослідження є підвищення ефективності лікування та визначення місця радіонуклідної терапії ${ }^{153} \mathrm{Sm}$ оксабіфором в лікуванні метастатичного ураження кісток при злоякісних пухлинах різної локалізації.

\section{ОБ'ЄКТ I МЕТОДИ ДОСЛІДЖЕННЯ}

У відділенні ядерної медицини Національного інституту раку проліковано 120 хворих з первинними пухлинами передміхурової залози та грудної залози і метастатичним ураженням кісток за допомогою ${ }^{153} \mathrm{Sm}$ оксабіфору, виробництва підприємства «Радіопрепарати» Інституту ядерної фізики Академії наук Республіки Узбекистан (реєстраційне свідоцтво Міністерства охорони здоров’я України № UA/12416/01/01 на термін 5 років).

Серед пролікованих хворих 75 з РГЗ, 45 - з РПЗ. 3 них 75 жінок і 45 чоловіків. Середній вік становить $55 \pm 11,6$ років. У 110 пацієнтів (90\%) наявність кісткових метастазів визначалася за допомогою остеосцинтиграфії (ОСГ) $3^{99 \mathrm{mT}}$ Тс-MDP. У 10 пацієнтів діагноз кісткового ураження верифікувався іншими методами променевої діагностики.

Препарат вводився внутрішньовенно з наступним скануванням у режимі «все тіло» за допомогою однофотонної емісійної комп’ютерної томографії (Siemens, Німеччина) через 1 год після введення радіоактивного фармацевтичного препарату (РФП). Визначення лікувальної дози препарату проводилося з розрахунку 1,5 мКи/кг маси тіла хворого. У 1 хворої, у якої маса тіла була менше 50 кг, доза була знижена до 1,0 мКи/кг маси тіла. 3 метою профілактики можливої нудоти всім хворим за 15 хв до введення ${ }^{153} \mathrm{Sm}$ оксабіфора внутрішньом'язово вводився метоклопрамід. Усі хворі ознайомлювалися та підписували форму Інформованої згоди.

Через 1 год після ін'єкції РФП проводилася ОСГ для візуалізації розподілу і характеру накопичення ${ }^{153} \mathrm{Sm}$.

Дослідження проводилися на $\gamma$-камері з використанням низькоенергетичного паралельного коліматора високого розрішення при налаштуванні на фотопік 140 кеВ і шириною вікна дискримінації 10\%. Запис діагностичного зображення 


\section{Оригінальні статті / Original Articles}

здійснювався через 60 хв після внутрішньовенного введення ${ }^{153} \mathrm{Sm}$ з наступними параметрами:

- розмір матриці $256 \times 1024$;

- швидкість просування столу, залежно від маси тіла пацієнта становила 6-10 см/хв;

- включена функція розпізнавання контуру тіла.

За необхідності здійснювалася планарна прицільна сцинтиграфія з розміром матриці $256 \times 256$ і набором не менше 500000 імпульсів на кадр (найчастіше - для отримання діагностичних образів в бічних і діагональних проекціях, рідше - як метод візуалізації дозволяє отримати більш статистично достовірне зображення, ніж сцинтиграфія всього тіла.

\section{РЕЗУЛЬТАТИ}

До призначення радіонуклідної терапії всі пацієнтки одержували хіміотерапевтичне лікування, бісфосфонати та гормони. Вираженість болю в кістках зменшувалася під впливом протипухлинних препаратів, однак ступінь зменшення больового синдрому з часом знижувався.

3 метою знеболення та профілактики переломів і подальшого метастатичного прогресування в кістках хворим за показаннями призначалася терапія ${ }^{153} \mathrm{Sm}$.

Хвора А., 1940 року народження, з діагнозом раку правої грудної залози, T2N2M1, стадія III, клінічна група II, направлена на лікування в Національний інститут раку. 09.07.2011 p. хворій була проведена ОСГ $3{ }^{99 \mathrm{~m} T c-M D P . ~ У с т а н о в л е н і ~ м н о-~}$ жинні метастази в кістки скелета - грудний відділ хребта (2-4-й грудні хребці, рівень накопичення РФП 250\%), поперековий відділ (5-й поперековий хребець, рівень накопичення РФП 190\%), тіло правої клубової кістки (рівень накопичення РФП 180\%), ліва стегнова кістка (рівень накопичення РФП $240 \%$ ) (рис. 1).

Враховуючи наявність вираженого больового синдрому, а також відсутність клініко-лабораторних протипоказань для проведення системної радіонуклідної терапії, пацієнтці було запропоновано лікування ${ }^{153} \mathrm{Sm} .22 .11 .2012$ р. у відділенні ядерної медицини Національного інституту раку, хворій А. було введено ${ }^{153} \mathrm{Sm}$ в дозі 3996,0 МБк з розрахунку 1,5 МБк на кг при масі тіла 72 кг. Під час і після введення препарату побічних ефектів не відзначалося. Через 1 год після ін'єкції РФП проводилася ОСГ для візуалізації розподілу і характеру накопичення ${ }^{153} \mathrm{Sm}$ (рис. 2).

Вогнища гіперфіксації РФП, виявлені на діагностичному скані, за локалізацією та площею ураження відповідають таким на ОСГ $3{ }^{153} \mathrm{Sm}$. Рівень накопичення ${ }^{153} \mathrm{Sm}$ перевищує рівень накопичення ${ }^{99 \mathrm{~m}} \mathrm{Tc}-\mathrm{MDP}$ більш ніж в 4,5 раза. Хворій А. рекомендована контрольна ОСГ через 3 міс.

Хвора Б., 1955 року народження, діагноз - рак правої грудної залози T3N3M1, стадія III, клінічна група II. Мета-

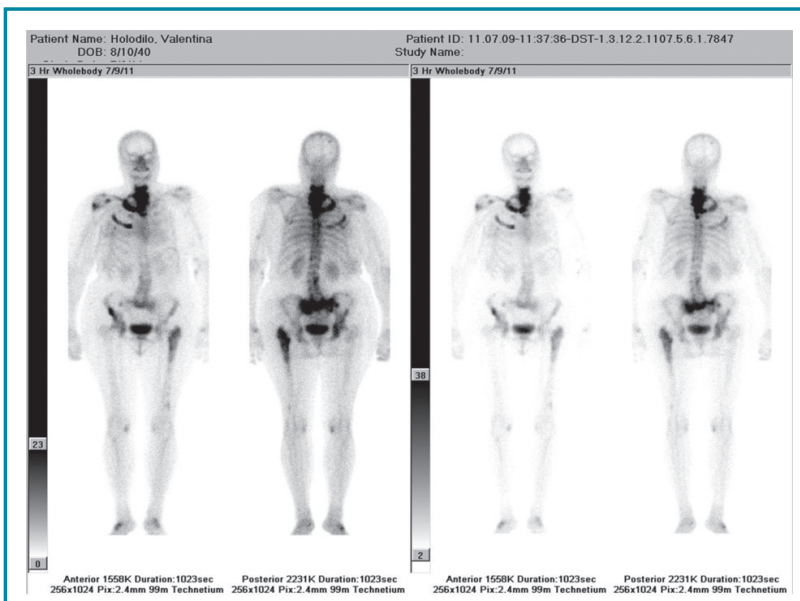

Рис. 1. Хвора А. ОСГ $3^{99 m}$ Tc-MDP статичне ураження кісток скелета підтверджується даними ОСГ від 06.08.2012 р. (рис. 3).

На скані всього тіла відзначаються осередки гіперфіксації РФП в грудному та поперековому відділах хребта, голівці лівої плечової кістки, 7-му і 8-му ребрах зліва. Враховуючи наявність вираженого больового синдрому, хворій Б. 23.11.2012 p. внутрішньовенно введено ${ }^{153} \mathrm{Sm}$ оксабіфор в дозі 3162,0 МБк. Під час і після введення препарату побічних ефектів не відзначалося. Через 1 год після ін'єкції РФП проводилася ОСГ для візуалізації розподілу і характеру накопичення ${ }^{153} \mathrm{Sm}$ (рис. 4). Відзначається інтенсивне накопичення лікувального РФП

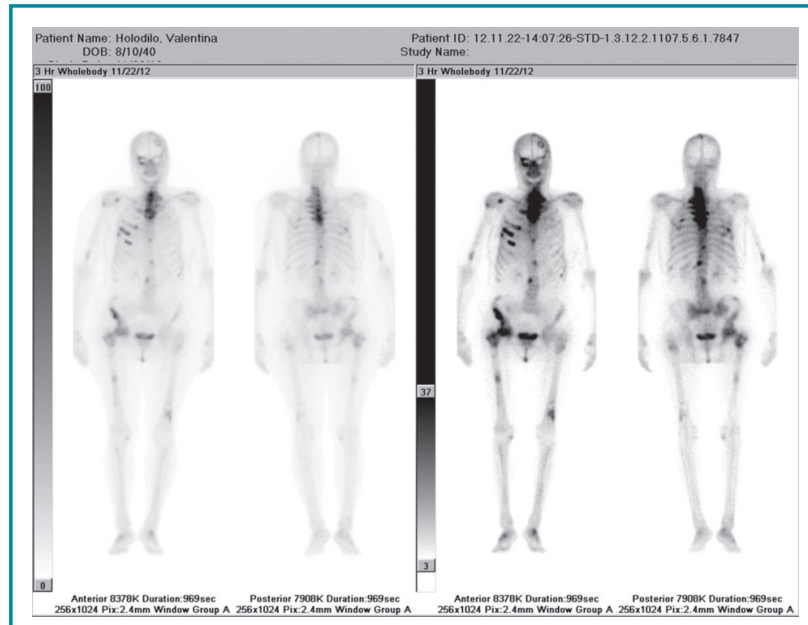

Рис. 2. Хвора А. ОСГ $3{ }^{153} \mathrm{Sm}$

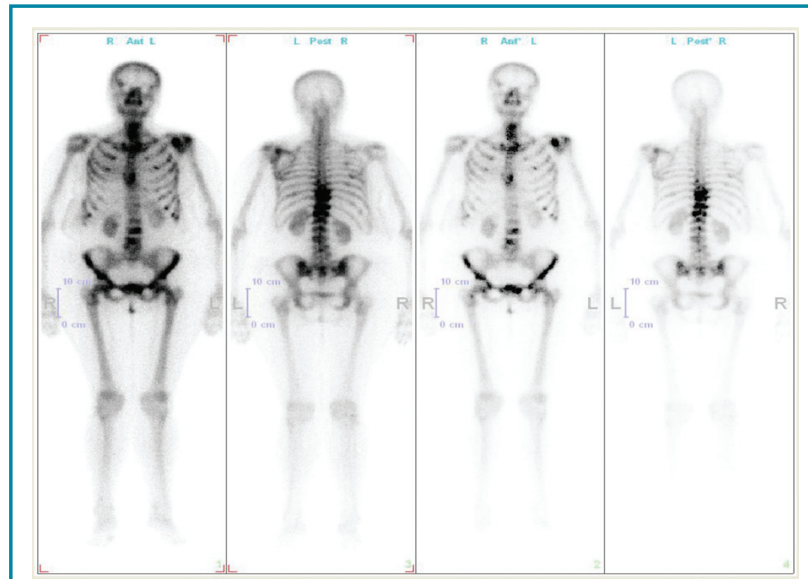

Рис. 3. Хвора Б. ОСГ $3^{99 m}$ Tс-MDP

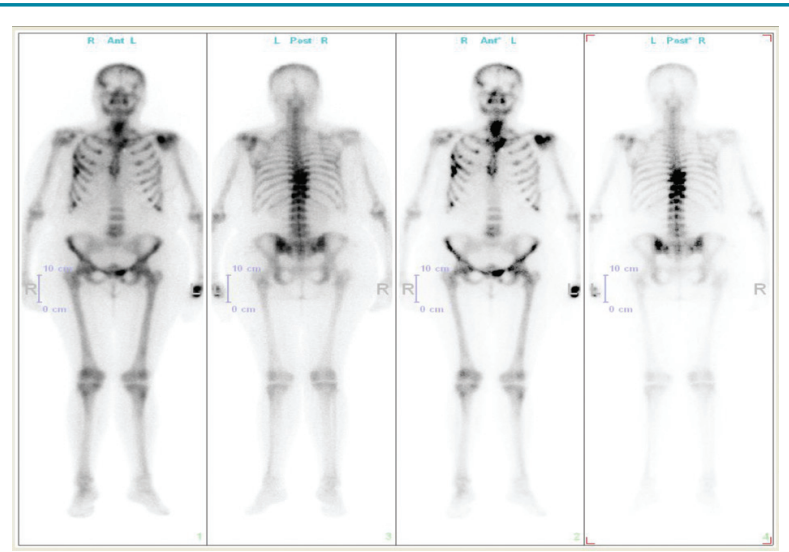

Рис. 4. Хвора Б. ОСГ $3{ }^{153} \mathrm{Sm}$ 
у всіх осередках, виявлених на діагностичному скані. Максимальний рівень накопичення (більше 500\%) встановлено у вогнищах грудного відділу хребта і голівці плечової кістки. Хворій Б. рекомендована контрольна ОСГ через 3 міс.

У 45 пацієнтів метастатичне ураження кісток виникло на фоні раку передміхурової залози. У всіх хворих спостерігався больовий синдром, який потребував збільшення кількості знеболювальних препаратів. У 41 хворого метастази в кістки верифіковані за допомогою ОС ${ }^{99 \mathrm{~m}} \mathrm{Tc}-\mathrm{MDP}$, у 4 - за допомогою інших методів діагностики. До проведення радіонуклідної терапії всі пацієнти одержували гормональне лікування та супровідну терапію бісфосфонатами. Причиною призначення радіонуклідної терапії став больовий синдром та збільшення кількості прийому знеболювальних препаратів. Так, пацієнта В. з метастатичним ураженням кісток на фоні раку передміхурової залози, з вираженим больовим синдромом було проліковано за допомогою ${ }^{153} \mathrm{Sm}$ оксабіфору. На скані всього тіла $3{ }^{99 \mathrm{~m}} \mathrm{Tc}-\mathrm{MDP}$ підтверджено наявність метастатичного ураження (рис. 5).

На ОСГ відображена сцинтиграфічна картина множинного ураження поперекового та сідничного відділів хребта і крила клубової кістки.

При скануванні через 1 год після введення ${ }^{153} \mathrm{Sm}$ одержано сцинтиграфічне зображення, яке підтверджує наявність метастатичних вогнищ, виявлених на скані $3{ }^{99 \mathrm{~m}} \mathrm{Tc}-\mathrm{MDP}$ (рис. 6).

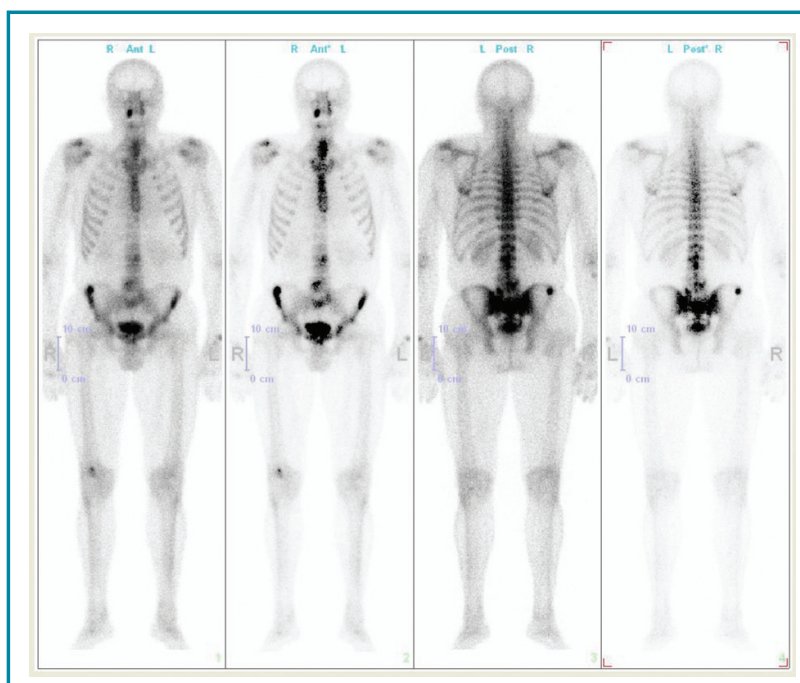

Рис. 5. Хворий В. ОСГ $3^{99 m}$ Tс-MDP

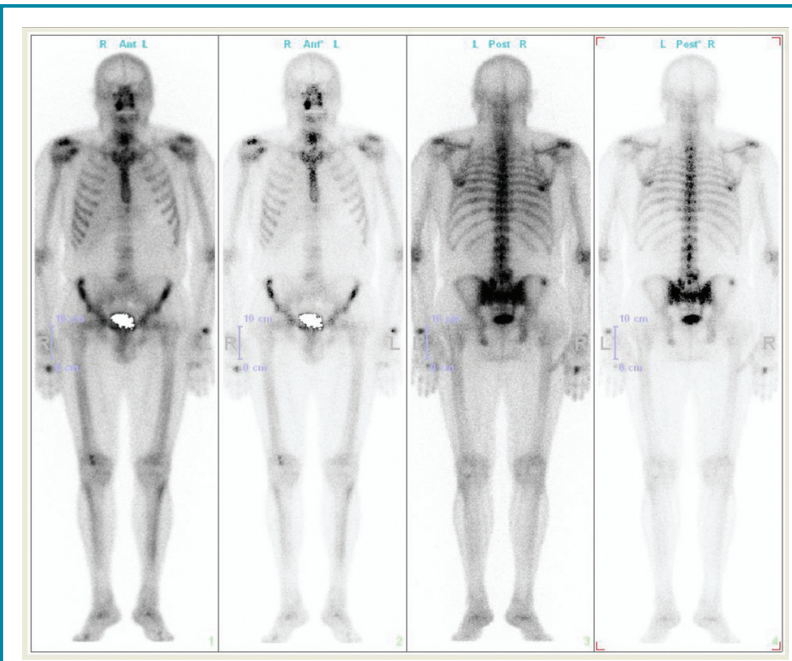

Рис. 6. Хворий В. ОСГ $3^{153} \mathrm{Sm}$
Діагностичні сканування, проведені через 3-4 міс після лікування ${ }^{153} \mathrm{Sm}$ у $75 \%$ супроводжувалися зменшенням больового синдрому, зниженням функціональної активності метастатичних вогнищ (нижчий відсоток накопичення РФП) та у $48 \%$ пацієнтів зменшувалася кількість вогнищ у кістках.

\section{вИСновКИ}

Радіонуклідна терапія $3{ }^{153} \mathrm{Sm}$ оксабіфором може бути застосована в комплексному лікуванні метастатичного ураження кісткової системи при злоякісних пухлинах різної локалізації. ${ }^{153} \mathrm{Sm}$ оксабіфор характеризується високим рівнем накопичення РПФ у метастатичному вогнищі при мінімальних побічних ефектах.

\section{СПИСОК ВИКОРИСТАНОÏ ЛІТЕРАТУРИ}

1. Hoskin, P.J., Stratford, M.R., Folkes, L.K. Regan, J, \& Yarnold, J.R. (2000). Effect of local radiotherapy for bone pain on urinary markers of osteoclast activity. The Lancet, 355(9213), 1428-1429. doi: 10.1016/s0140-6736(00)02144-9.

2. Palmedo, H., Manka-Waluch, A., Albers, P., Schmidt-Wolf, I.G., Reinhardt, M., Ezziddin, S., \& Biersack, H.J. (2003). Repeated bone-targeted therapy for hormonerefractory prostate carcinoma: randomized phase II trial with the new, high-energy radiopharmaceutical rhenium-188 hydroxyethylidenediphosphonate. Journal of Clinical Oncology, 21(15), 2869-2875. doi: 10.1200/JCO.2003.12.060.

3. Боброва, В.М., Грушка, Г.В., Стадник, Л.Л., Ткаченко, Г.І., Луховицька, Н.І., Савченко, А.С., Ріяко, В.М., \& Підченко, Н.С. (2016). Динаміка гематологічних показників при проведенні радіонуклідної терапії ${ }^{153} \mathrm{Sm}$-оксабіфором у онкологічних хворих. Український радіологічний журнал, 1, 166.

4. Крылов, В.В. (2007). Радионуклидная терапия самарием ${ }^{153}$ Sт при метастатическихпоражениях костей. (Дис. д-ра мед. наук). Медицинский радиологический научный центр РАМН, Обнинск

5. Marcus, C., Saeed, S., Mlikotic, A., Mishkin, F., Pham, H.L., Javellana, T., Diestelhorst, S. \& Minami, C. (2002). Lack of effect of a bisphosphonate (pamidronate disodium) infusion on subsequent skeletal uptake of Sm-153-EDTMP. Clinical Nuclear Medicine, 27(6), 427-430. doi: 10.1097/00003072-200206000-00008.

6. Russo, L.P. (2001). Analysis of skeletal-related events in breast cancer and response to therapy. Seminars in Oncology, 28(4), 22-27. doi: 10.1016/s0093-7754(01)90228-3

Clinical cases of treatment of bone lesions in breast and prostate cancer (radionuclide therapy).

V.V. Danilenko, G.G. Sukach, O.I. Solodyannikova, D.L. Sagan National Cancer Institute, Kyiv

Abstract. Objective. The purpose is to increase the effectiveness of treatment and to determine the place of radionuclide therapy with samarium $\left({ }^{153} \mathrm{Sm}\right)$ oxabiphor in the treatment of metastatic bone damage in malignant tumors of different localization. Materials and methods. The results of treatment of 120 patients with ${ }^{153} \mathrm{Sm}$ oxabiphor with primary tumors of the prostate and breast with metastatic bone damage were analyzed. The observation group consisted of 75 patients with breast cancer and 45 patients with prostate cancer. Results. Prior to the appointment of radionuclide therapy, all patients with breast cancer received chemotherapy treatment, bisphosphonates and hormones. Bone pain decreased under the influence of anticancer drugs, but the degree of reduction of pain syndrome decreased over time. All patients with prostate cancer were experiencing pain syndrome, which required an increase in the number of painkillers. Before to radionuclide therapy, all patients received hormonal treatment and concomitant bisphosphonate therapy. The reason for prescribing radionuclide therapy was increasing pain syndrome and increasing the number of painkillers. For the purpose of anesthesia and prevention of fractures and subsequent metastatic progression in the bones, patients were prescribed ${ }^{153} \mathrm{Sm}$ therapy. Diagnostic scanning was performed 3-4 months after treatment with ${ }^{153} \mathrm{Sm}$. As a result of treatment, the pain syndrome decreased, decreased functional activity of metastatic foci (a lower percentage of accumulation of radiopharmaceutical was observed in $75 \%$, and in $48 \%$ of patients a decrease in the number of foci in the bones was observed. Conclusion. It is proved that radionuclide therapy with ${ }^{153} \mathrm{Sm}$ oxabiphor can be used in the complex treatment of metastatic lesions of the skeletal system in malignant tumors of different localization. ${ }^{153} \mathrm{Sm}$ oxabiphor is characterized by a high level of radiopharmaceutical accumulation in the metastatic focus with minimal side effects.

Key words: breast cancer, prostate cancer, samarium oxabiphor $\left({ }^{153} \mathrm{Sm}\right)$, metastatic bone damage. 


\section{Оригінальні статті / Original Articles}

\section{Клинические случаи лечения костного поражения при раке грудной железы и предстательной железы (радионуклидная терапия). \\ В.В. Даниленко, Г.Г. Сукач, О.И. Солодянникова, Д.Л.Саган Национальный институт рака, Киев}

Резюме. Цель. Цель исследования - повысить эффективность лечения и определить место радионуклидной терапии самарием $\left({ }^{153} \mathrm{Sm}\right)$ оксабифором в лечении метастатического поражения костей при злокачественных опухолях различной локализации. Объект и методы. Результаты лечения с помощью ${ }^{153} \mathrm{Sm}$ оксабифора 120 больных с первичными опухолями предстательной железы и грудной железы и метастатическим поражением костей. В группу наблюдения вошли 75 пациенток с раком молочной железы и 45 пациентов с раком предстательной железы. Результаты. До назначения радионуклидной терапии все пациентки с раком молочной железы получали химиотерапевтическое лечение, бисфосфонаты и гормоны. Выраженность боли в костях уменьшалась под влиянием противоопухолевых препаратов, однако степень уменьшения болевого синдрома со временем снижалась. У всех больных раком предстательной железы наблюдался болевой синдром, требующий увеличения количества обезболивающих препаратов. Причиной назначения радионуклидной терапии стало увеличение выраженности болевого синдрома и количества приемов обезболивающих препаратов. С целью обезболивания и профилактики переломов и дальнейшего метастатического прогрессирования в костях больным по показаниям назначалась терапия ${ }^{153} \mathrm{Sm}$. Диагностическое сканирование проводили через 3-4 мес после лечения ${ }^{153} \mathrm{Sm}$. У $75 \%$ пациентов отмечено уменьшение болевого синдрома, снижение функциональной активности метастатических очагов (низкий процент накопления радиоактивного фармацевтического препарата и у $48 \%$ пациентов уменьшалось количество очагов поражения в костях. Bыводы. Доказано, что радионуклидная терапия с ${ }^{153} \mathrm{Sm}$ оксабифором может быть применена в комплексном лечении метастатического поражения костной системы при злокачественных опухолях различной локализации. ${ }^{153} \mathrm{Sm}$ оксабифор характеризуется высоким уровнем накопления радиоактивного фармацевтического препарата в метастатическом очаге при минимальных побочных эффектах.

Ключевые слова: рак грудной железы, рак предстательной железы, самарий оксабифор $\left({ }^{153} \mathrm{Sm}\right)$, метастатическое поражение костей.

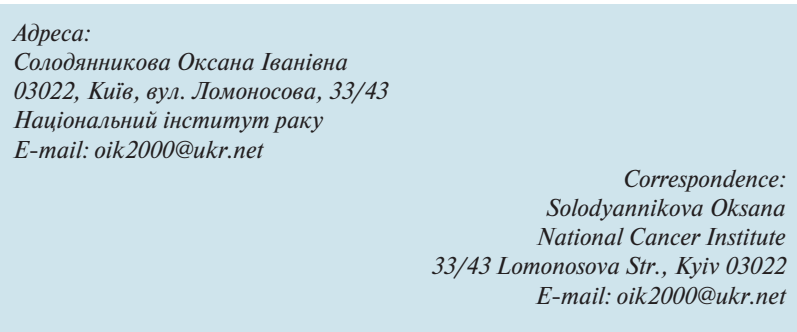

